\title{
SPATIAL ATTENTIONAL SHIFTS: FURTHER EVIDENCE FOR THE ROLE OF POLYSENSORY MECHANISMS USING VISUAL AND TACTILE STIMULI
}

\author{
Charles M. Butter, ${ }^{*}$ Henry A. Buchtel and Richard Santucci $\dagger$ \\ University of Michigan and Ann Arbor V A Medical Center, U.S.A.
}

(Received 22 December 1988; accepted 3 June 1989)

\begin{abstract}
Normal subjects performed simple reaction time responses to lateralized visual target stimuli (Experiment 1) and lateralized tactile target stimuli (Experiment 2). In each experiment, the lateralized targets were preceded at one of four intervals by a visual or tactile cue located on the same (valid cue), or opposite (invalid cue) side, or on both sides (neutral cue). The validity of the visual and tactile cues influenced the speed of response to either target stimulus. These findings, together with those previously reported (BUCHTEL and BUTTER, Neuropsychologia 26, 499-509, 1988), are consistent with the view that intra- and inter-modal spatial cueing is effective with modalities that are linked to orienting systems in which movements of the sensory array serve to improve sensory analysis.
\end{abstract}

\section{INTRODUCTION}

STUDIES of spatially-directed attention have generally used visual cues to direct attention toward or away from visual targets $[17,22]$. POSNER [21], using symbolic cues, has reported that visual cues apparently lack this capacity to direct attention spatially when the target stimuli are in other modalities, except when the subjects are required to discriminate between target stimuli. In a further examination of this question, using spatial rather than symbolic cues, BuCHTEL and ButTer [2] reported that auditory as well as visual spatial cues produce costs and benefits in reaction times (RTs) to visual target stimuli, but not to auditory target stimuli. They suggested that these findings may be understood by positing that spatial cues shift attention to a new location in space only when the targets are linked to an orienting system controlling movements, such as eye movements, that when activated can improve stimulus identification because of the sense organs' spatial gradient of acuity. By this formulation, responses to auditory targets were not influenced by pre-cues because in humans there is no auditory "fovea" or natural, reflexive motor response that serves to improve auditory analysis. The tactile system does have the property of a spatial gradient of acuity: tactile stimuli can evoke orienting movements of the hand or other body part in order to identify a tactile stimulus by bringing more sensitive portions of the skin (e.g. finger tips) to bear on the object. Thus, a spatial gradient hypothesis would predict that when tactile target stimuli are used in a RT task, non-tactile as well as tactile spatial cues would be effective in shifting attention toward them. It would also be expected that tactile spatial cues, like

\footnotetext{
*To whom correspondence should be addressed at: Neuroscience Building, University of Michigan, Ann Arbor, MI 48109-1687, U.S.A.

$\nmid$ Now at Baylor Medical School, Houston, Texas, U.S.A
} 
auditory cues, would be effective in shifting attention spatially when visual target stimuli are used. Two experiments were carried out to test these predictions. Experiment 1 tested the influence of visual and tactile cues on responses to visual targets; Experiment 2 tested the effect of these same cues on responses to tactile targets.

\section{EXPERIMENT 1}

\section{Methods}

Subjects. Ten men, 1925 years of age (median age $=26$ years), served as the subjects. All were right-handed by self-report and had normal vision or were corrected to normal. Four of the subjects were aware of the purpose of the experiment and were not paid to participate. The other six subjects were una ware of the purpose of the experiment and were paid $(\$ 5.00 / \mathrm{hr})$ for their participation.

Apparatus and procedures. The visual targets were provided by two, red light-emitting diodes (LEDs) located 10 . to the left and right of a yellow/green LED located at the centre of a black tangent screen positioned $57 \mathrm{~cm}$ from the subject. The visual cues were provided by four red LEDs arranged in a square pattern around each target lamp; each cue lamp was located approx $1.8^{\circ}$ from the target lamp and subtended $0.48^{\circ}$ of visual angle. Each tactile cue was provided by four blunt metal rods, each $0.64 \mathrm{~mm}$ in dia., arranged in a square pattern and separated by $0.7 \mathrm{~cm}$. The tips of the rods were flush with the plate on which the subject's index finger rested during lesting; this plate was located $2.2 \mathrm{~cm}$ below each of the visual target-lamps. The four rods of each tactile cue were rigidly attached to each other and were simultaneously displaced $2.5 \mathrm{~mm}$ by an electrically-activated solenoid and in this way made contact with the subject's finger-tip resting on the overlying plate. The rise and fall times of the tactile cues were less than $5 \mathrm{msec}$. The solenoids and rods for the tactile cues were enclosed in a box containing sound-deadening materials, which together with the white noise provided by a speaker located in the testing room, masked the sound produced by the solenoids.

During testing, the subject sat directly facing the display screen, with his chin resting in a molded support. Both arms, resting on padded supports, were extended straight ahead toward the screen and below it so that the index finger of each hand rested on the surface through which the tips of the tactile target rods protuded when the appropriate solenoid was activated. The subject's arms were covered with black drapes so that they did not reflect light from the LEDs on the display screen.

At the start of each trial, the subjects fixated the central spot and then pressed a pedal with the right foot in order to close a microswitch. Between 0.5 and 2.0 sec later, a single lateral cue, $50 \mathrm{msec}$ in duration, was presented on $69 \%$ of the trials; on $21 \%$ of the trials (neutral trials) both cues were presented simultaneously for $50 \mathrm{msec}$. The remaining trials $(10 \%)$, were "catch trials" in which no target was presented following the cue to ensure that the subjects responded to the target rather than in anticipation of a target after the cue. On trials in which targets appeared, the times between cue onset and target onset, or the stimulus onset asynchrony (SOA), were 50, 150, 400 and 1000 msec. The subjects released the switch when they detected the target and the target remained present until this response. If the subject did not respond within $600 \mathrm{msec}$ after the target's onset, a "non-response" was recorded and the trial terminated. On $80 \%$ of the trials with a single, lateralized cue, the cue was presented on the same side as the target (valid cue); on the remaining $20 \%$ of single-cue trials, the cue was presented on the side opposite that of the target (invalid cue). Responses made less than $100 \mathrm{msec}$ after the onset of a target were regarded as anticipations and were discarded. The session was halted if a subject made 15 anticipations and/or responses on catch trials; the subject was told to be more careful and the session was repeated. The different types of trials (valid, invalid, neutral and catch trials) were presented in a pseudorandom order, as were the side on which target was presented and the four SOAs. Presentation of stimuli and determination of RTs were under the control of a microcomputer.

In the first session the subjects practiced the task. In their instructions they were told to release the microswitch as quickly as possible when a visual target appeared and to expect the target to appear predominantly on the side where the (single) cue was presented. In the practice session, subjects completed 696 trials with the visual cue and an equal number with the tactile cue. Although the results of this session were not included in data analyses, they were used to screen subjects to ensure that the validity of visual cues influenced RTs to visual targets as had been the case for subjects in BUCHTEL and BCTTER [2] This was done to eliminate the possibility that a negative finding with tactile stimuli might be caused by the inclusion of subjects who were not susceptible to cueing effects. Two potential subjects were eliminated because their responses did not show this effect.

The remaining four sessions, approx 50 min duration, each started with 16 warm-up trials the results of which were discarded. They were followed by two blocks of 696 trials each, in one of which the visual cue was presented and in the other, the tactile cues was presented. The order of presentation of the two cues was counterbalanced in an ABBA order. One-half of the subjects started the first session with the visual cue; the other started the first session with the tactile cue.

\section{Results}

The median RTs of each subject were averaged over the four testing sessions and analyzed with a repeated-measures, mixed design ANOVA including the order in which the subjects were tested (the between subjects factor) 
and four within-subjects factors: cue modality (visual vs tactile), cue validity (valid, neutral, invalid) SOA $(50,150,400$ and $1000 \mathrm{msec})$ and field in which the visual target was presented (left vs right). Median RTs averaged over subjects at particular combinations of factors were compared using by one-tail $t$-tests (if directional differences were predicted) or two-tail tests, and adjusting the confidence interval of 0.05 and 0.01 for the number of comparisons in each series (Bonferroni method).
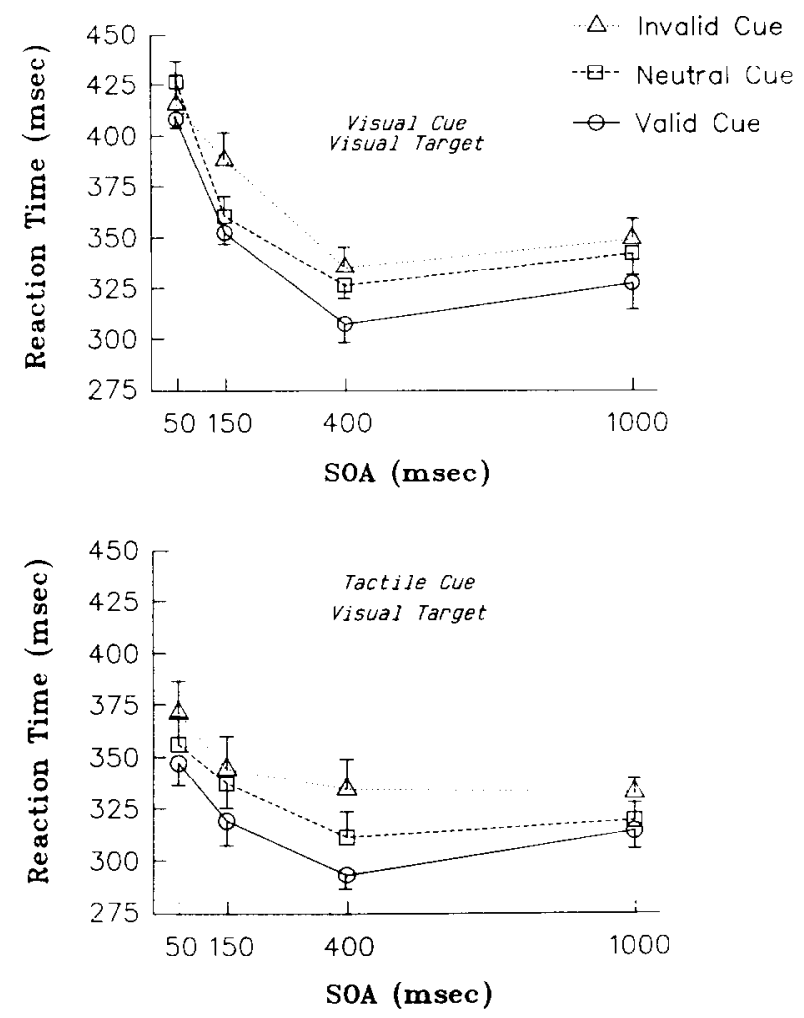

Fig 1. Mean reaction times to the visual target for the four stimulus onset asynchronies (SOAs), the three validity conditions, and with visual cue (above) and tactile cue (below) (Experiment 1).

Figure 1 shows how RTs varied with SOA in each of the validity conditions when the visual cue and the tactile cue were presented. As expected, when the visual cue preceded the visual targets, RTs were shortest when it was valid and longest when it was invalid. The same validity effects were obtained when the tactile cue was presented, as shown in the lower half of Fig. 1. As can be seen in Table 1, the effects of visual cue validity (RTs to invalid cues vs RTs to valid cues) were significant at all SOAs except for the shortest one. Furthermore, the visual cue yielded significant benefits (RTs to neutral cues vs RTs to valid cues) at two SOAs ( 50 and $400 \mathrm{msec}$ ), and the benefit approached significance at the shortest SOA $(50 \mathrm{msec})$; the invalid cue yielded a significant cost (RTs to invalid cues vs RTs to neutral cues) at only one SOA (150 msec). Inspection of Table 1 also shows that the tactile cue was associated with significant validity effects at all SOAs; it also yielded a significant benefit at one SOA ( $400 \mathrm{msec})$, a benefit that approached significance at the shortest SOA $(50 \mathrm{msec})$, and significant costs at two SOAs (150 and $400 \mathrm{msec})$.

Whereas the two cues had similar effects on performance, as described above, these effects were not identical. The interaction of cue modality, validity and SOA was significant $(F=3.82 ;$ d.f. $=6 / 4 ; P<0.0035)$, indicating that the cue effects differed from each other at particular SOAs. Analysis of this effect revealed that only at $50 \mathrm{msec}$ did cue modality have a significant effect on validity; the validity effect of the tactile cue $(23.7 \mathrm{msec})$ was significantly greater than that of the visual cue $(7.4 \mathrm{msec})(t=2.95 ;$ d.f. $=19 ; P<0.005)$ at this SOA. This greater effect of the tactile cue on validity was apparently due to the finding that the cost of the tactile cue was greater than that of the visual cue at the $50 \mathrm{msec} \operatorname{SOA}(t=4.75 ;$ d.f. $=19 ; P<0.005)$. In addition, the visual cue had a greater cost than the tactile cue at $150 \mathrm{msec}$ SOA $(t=3.84 ;$ d.f. $=19 ; P<0.005)$. Furthermore, cue modality interacted significantly with SOA $(F=23.07$; d.f. $=3 / 24 ; P<0.001)$. As can be seen in Fig. 2 , this interaction resulted from the relatively greater 
Table 1. $t$-Values for validity effects, costs and benefits with visual and tactile cues in Experiment 1.

\begin{tabular}{|c|c|c|c|c|}
\hline & & $\begin{array}{c}\text { Validity effects } \ddagger \\
\mathrm{RT}_{\text {(invalid) }}-\mathrm{RT}_{\text {(valid) }}\end{array}$ & $\begin{array}{c}\text { Costs } \\
\mathrm{RT}_{+}^{+} \\
\text {(invalid) }\end{array}$ & $\begin{array}{c}\text { Benefits } \\
R T_{\text {incutral) }}-\mathrm{RT}_{\text {(valid }}\end{array}$ \\
\hline Cue & SOA & & & \\
\hline Visual & $\begin{array}{r}50 \\
150 \\
400 \\
1000\end{array}$ & $\begin{array}{l}1.341 \mathrm{~ns} \\
6.649 \dagger \\
5.127 \dagger \\
3.859 \dagger\end{array}$ & $\begin{array}{c}-1.993 \mathrm{~ns} \\
5.054 \dagger \\
1.576 \mathrm{~ns} \\
1.141 \mathrm{~ns}\end{array}$ & $\begin{array}{l}3.333^{*} \\
1.594 \mathrm{~ns} \\
3.551^{*} \\
2.717 \text { appr. signif. }\end{array}$ \\
\hline Tactile & $\begin{array}{r}50 \\
150 \\
400 \\
1000\end{array}$ & $\begin{array}{r}4.293 \dagger \\
8.630^{\dagger} \\
14.056 \dagger \\
3.207^{*}\end{array}$ & $\begin{array}{l}1.540 \mathrm{~ns} \\
3.261^{*} \\
3.152^{*} \\
0.636 \mathrm{~ns}\end{array}$ & $\begin{array}{l}2.754 \text { appr. signif. } \\
1.214 \mathrm{~ns} \\
4.130 \dagger \\
2.319 \mathrm{~ns}\end{array}$ \\
\hline
\end{tabular}

* Significant $P \leq 0.05$.

+ Significant $P \leq 0.01$.

${ }_{+}^{+}$For 4 comparisons $P_{0.05}=0.0125$, for one-tail $t$-tests, $($ d.f. $=19)$ critical $t_{0} 05=2.450 ;$ critical $t_{n .01}=3.430$.

$\S$ For 8 comparisons $P_{0.05}=0.00625$, for one-tail $t$-tests $(d . f=19)$ critical $t_{0.05}=2.775 ;$ critical $t_{0.01}=3.725$.

improvements in RT associated with the visual cue than with the tactile cue as SOA increased. Tests of individual mean RTs at particular SOAs disclosed that the RT improvements from $50150 \mathrm{msec}$ and from 150400 msec were larger with the visual cue than with the tactile cue (improvement from $50150 \mathrm{msec} ; t=4.03 ;$ d.f. $=27 ; P<0.005$; improvement from $150400 \mathrm{msec} ;=3.96 ;$ d f. $=27 ; P<0.005$ ). Finally, the cue modality $\times$ validity $\times$ field $\times$ SOA interaction was significant $(F=2.91$; d.f. $=6 / 48 ; P=0.0167)$ but has no obvious interpretation.

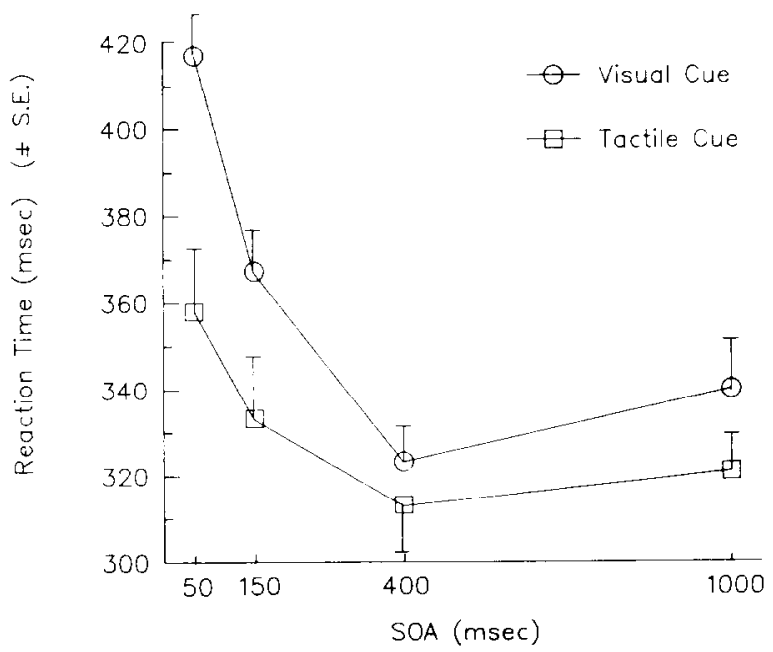

Fig 2. Mean reaction times to the visual target for the four stimulus onset asynchronies (SOAs) with visual and tactile cues (Experiment 1).

\section{EXPERIMENT 2}

Methods

Subjects. The subjects were ten men from 19-52 years of age (mean age $=26$ years). Four of the subjects had served in the previous experiment; they were aware of the purpose of the experiment and were not paid for participating. The remaining subjects had not participated in the previous experiment. They were unaware of the purpose of the 
experiment and were paid $(\$ 5.00)$ for participating. These men, like those who previously participated, were righthanded by self-report and had normal or corrected vision.

Apparatus and procedures. The apparatus was identical to that used in Experiment 1, except that the targets were tactile rather than visual. Each tactile target was provided by a rod that was positioned in the centre of the array of tactile cues described in Experiment 1 on the left and right sides. The diameter of the rod tips was $0.93 \mathrm{~mm}$. The rods were attached to solenoids which could displace the rod upward so as to come into contact with and displace the skin of the subject's index finger to the same extent described for the tactile cues in the previous experiment. The rise and fall times of the target rods were the same as for the cue rods. The tactile and visual cues were the same as those used in Experiment 1.

In each of four testing sessions, the subjects were tested with visual cues in one block of trials and tactile cues in another block, as in Experiment 1. The testing procedures, including randomization of stimulus conditions and balancing of order effects, were identical to those used in Experiment 1.

\section{Results}

The RT data from the 10 subjects were analyzed in the same ways described previously. Figure 3 shows the average median RTs to the tactile target as a function of SOA and validity, with tactile cues and visual cues. Comparing the findings in this figure to those in Fig. 1, it is clear that the effects of cues in the same modality as the targets are similar to one another. Furthermore, it appears that the validity of both cues affected RTs to tactile targets. This conclusion is supported by the results of statistical analyses of validity effects, which showed that with either the tactile or visual cue, these effects were significant at all but the longest (1000 msec) SOA (see Table 2). When costs and benefits of cues in each modality at particular SOAs were analyzed, the following outcomes were obtained. With the visual cue, there were significant benefits at two SOAs $(150 \mathrm{msec}$ and $400 \mathrm{msec})$ and a single significant cost $(50 \mathrm{msec})$. With the tactile cue, there were significant benefits at two SOAs (50 and $150 \mathrm{msec})$ and a single significant cost $(150 \mathrm{msec})$.

The modality in which the cue was presented also had significant effects on cue validity and on the RT improvement resulting from increasing the SOA. With regard to the latter finding, as seen in Fig. 4, the tactile cue was associated with greater RT improvements at short SOAs than was the visual cue; this finding is supported by the significant interaction of cue modality and SOA $(F=23.07 ;$ d.f. $=3 / 24 ; P<0.0001)$. Analyses of this interaction disclosed that the RT improvements from $50-150$ and from $150400 \mathrm{msec}$ were significantly larger when the tactile cue was presented than they were when the visual cue was presented (50-150 msec: $t=14.22$; d.f. $=27 ; P<0.005 ; 150-400$ msec: $t=2.45$; d.f. $=27 ; P<0.025$ ). With regard to the effect of cue modality on validity, the interaction of these two factors was significant $(F=8.43$; d.f. $=2.16 ; P<0.0033)$. As seen in Fig. 5 , the benefit resulting from a valid tactile cue appeared greater than the benefit resulting from a valid visual cue. This finding is supported by analyses of the simple effects of the cue modality $\times$ validity interaction: the benefit of the tactile cue was significantly greater than that of the visual cue $(t=4.26 ;$ d.f. $=79 ; P<0.001)$. Furthermore, the interaction of cue modality with validity and SOA was significant $(F=3.82$; d.f. $=6 / 4 ; P<0.0035)$, apparently as a result of the significantly greater validity effects exerted by the tactile cue relative to those exerted by the visual cue at 50 and $150 \mathrm{msec}$ (at $50 \mathrm{msec}: t=8.15$; d.f. $=19 ; P<0.001$; at $150 \mathrm{msec}: t=5.04$; d.f. $=19 ; P<0.001)$. In addition, the test $\times$ validity $\times$ field $\times \mathrm{SOA} \times$ order interaction was significant $(F=3.69 ;$ d.f. $=6 / 48 ; P<0.0044)$.

These differences in validity effects, in turn, are accounted for by the finding that the tactile cue, compared to the visual cue, had a significantly greater benefit at $50 \mathrm{msec}(t=10.05$; d.f. $=19 ; P<0.001)$ and a significantly greater cost at $150 \mathrm{msec}(t=3.81 ;$ d.f. $=19 ; P<0.005)$. There were two other significant higher-order interactions in which cue modality was a factor: the cue modality $\times$ field $\times$ validity $\times$ SOA interaction $(F=2.84 ;$ d.f. $=6 / 48 ; P<0.021)$, 

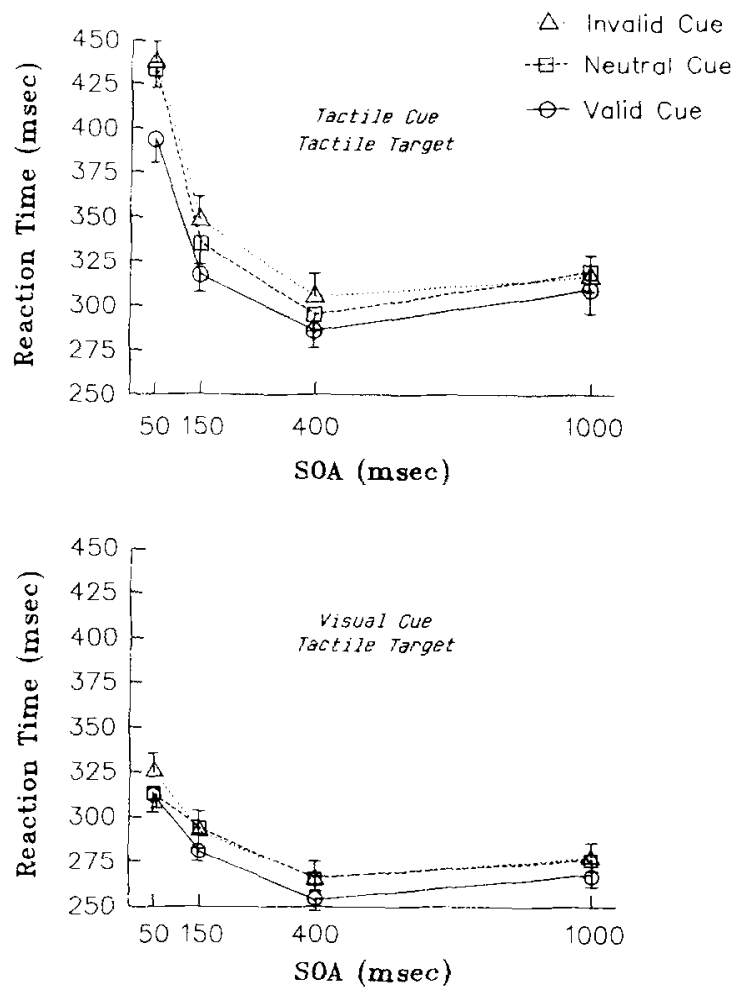

Fig 3. Mean reaction times to the tactile target for the four stimulus onset asynchronies (SOAs), the three validity conditions and with tactile cue (above) and visual cue (below) (Experiment 2 ).

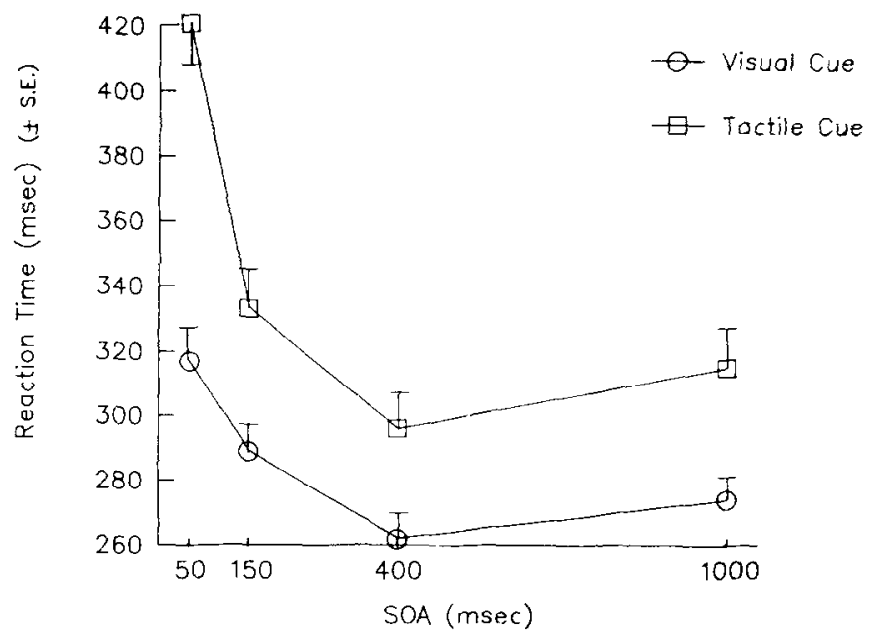

Fig 4. Mean reaction times to the tacl. target for the four stimulus onset asynchronies (SOAs) with visual and tactile cues (Experiment 2). 


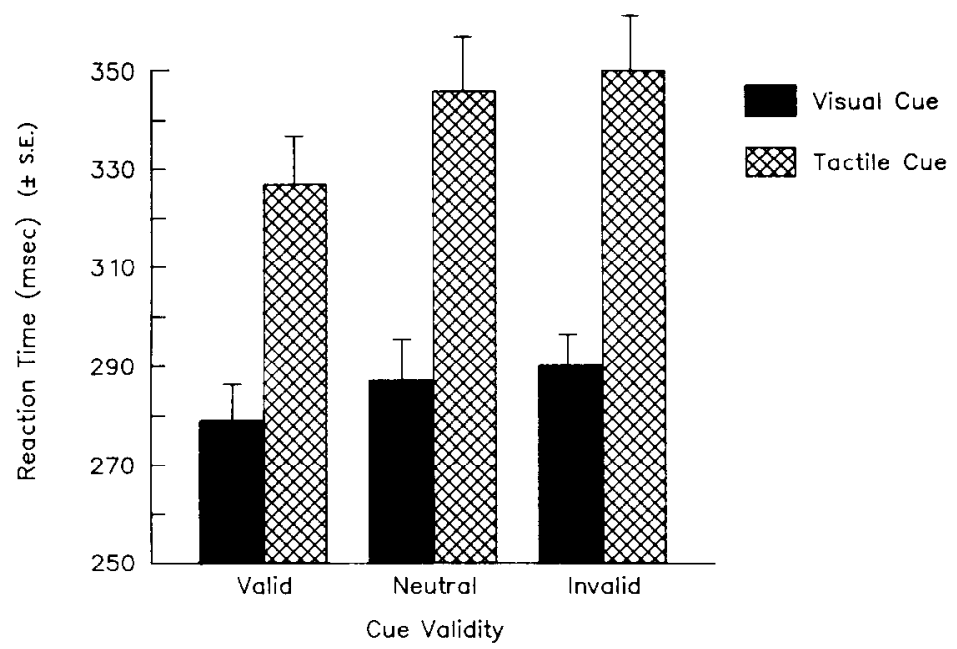

Fig 5. Mean reaction times to the tactile target for the three validity conditions with visual and tactile cues (Experiment 2).

Table 2. $t$-Values for validity effects, costs and benefits with visual and tactile cues in Experiment 2.

\begin{tabular}{|c|c|c|c|c|}
\hline & & 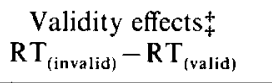 & 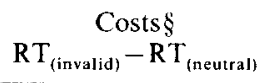 & 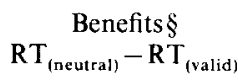 \\
\hline Cue & SOA & & & \\
\hline Visual & $\begin{array}{r}50 \\
150 \\
400 \\
1000\end{array}$ & $\begin{array}{l}3.159^{*} \\
3.029^{*} \\
3.342^{*} \\
2.402 \text { appr. signif. }\end{array}$ & $\begin{array}{l}3.290^{*} \\
0.418 \mathrm{~ns} \\
0.131 \mathrm{~ns} \\
0.366 \mathrm{~ns}\end{array}$ & $\begin{array}{l}0.026 \mathrm{~ns} \\
3.446^{*} \\
3.473^{*} \\
2.037 \mathrm{~ns}\end{array}$ \\
\hline Tactile & $\begin{array}{r}50 \\
150 \\
400 \\
1000\end{array}$ & $\begin{array}{l}11.227 \dagger \\
8.068 \dagger \\
5.039 \dagger \\
1.802 \mathrm{~ns}\end{array}$ & $\begin{array}{l}1.227 \mathrm{~ns} \\
3.290^{*} \\
2.585 \mathrm{~ns} \\
0.731 \mathrm{~ns}\end{array}$ & $\begin{array}{l}10.078 \dagger \\
4.778 \dagger \\
2.454 \mathrm{~ns} \\
2.533 \mathrm{~ns}\end{array}$ \\
\hline
\end{tabular}

* Significant $P \leq 0.05$.

$\dagger$ Significant $P \leq 0.01$.

${ }_{\ddagger}^{\ddagger}$ For 4 comparisons $P_{0.05}=0.0125$, for one-tail $t$-tests, $($ d.f. $=19)$ critical $t_{0.05}=2.450$; critical $t_{0.01}=3.430$.

$\$$ For 8 comparisons $P_{0.05}=0.00625$, for one-tail $t$-tests $($ d.f. $=19)$ critical $t_{0.05}=2.775 ;$ critical $t_{0.01}=3.725$.

which was apparently due to the greater benefit with the tactile cue than with the visual cue at $50 \mathrm{msec}$ being more apparent when targets were presented on the left than it was when targets were presented on the right. In addition, the cue modality $\times$ validity $\times$ field $\times \mathrm{SOA} \times$ order of testing with the two cues was significant $(F=3.69$; d.f. $=6 / 48 ; P<0.0044)$.

\section{DISCUSSION}

On the basis of our prior research on the effectiveness of visual and auditory cues in shifting attention spatially [2], we predicted that: (a) lateralized tactile or lateralized visual cues would influence RTs to lateralized visual targets; and (b) lateralized tactile or visual cues 
would influence RTs to lateralize tactile targets. The expected effects with visual targets were strong and consistent, and, with tactile targets, clearly present, although somewhat weaker. Our hypothesis that the effects of cue validity on RTs depend on the target's sensory modality possessing a "spatial acuity gradient" is thus supported by these findings. According to this view, the finding that RTs to auditory targets are not influenced by the spatial position of visual and auditory cues [2] is due to the lack of a reflexive response (such as pinnae movements in some non-human species) that would improve detection or identification of auditory targets. (For a discussion of the localizability of the auditory cues and targets, see $[2])$.

Since our hypothesis implies a relationship between shifts of attention and overt orienting to visual and tactile stimuli, a brief review of investigations relevant to this relationship (all involving visual stimuli) would be appropriate. Whereas there is considerable evidence that attention can shift spatially in the absence of eye movements $[7,17]$, some tasks in which eye movements and attention shifts have been jointly studied show that the two are closely associated [19, 20] and linked in time [21]. A close relationship between these two processes is also shown by the finding that subjects identify briefly presented letters better when the letters are on the side of space where they first move thcir cyes after the letters disappear [4] and the finding that eye movements in the direction of a peripheral target enhance its detection [23]. The results of neurobehavioral investigations also support the view that overt and covert orienting are closely linked. Selective deficits in performing eye movements in a particular direction are associated with selective deficits in shifting attention in the same direction in brain-damaged patients [18] and in cats with experimentally-produced lesions [14]. Electrophysiological findings also suggest a relationship between eye movements and selective attention to the visual target of the movement. When an appropriately aimed saccade is directed to a visual stimulus, the response of certain units in the primate superior colliculus $[10,26]$ and frontal eye fields $[9,25]$ to the stimulus are enhanced. Whereas the findings cited above provide wide-ranging support for a relationship between eye movements and attention, it should be noted that the direction of eye movements and attention can be dissociated under some conditions $[17,22]$. Thus, while there is a close functional relationship between overt and covert orienting to visual stimuli, this relationship is not obligatory.

A secondary finding from the present study - the shapes of the curves relating RTs to SOA-deserves comment and further analysis. Whereas these curves are similar for the four cue-target combinations we employed, two differences are worth noting. First, it is clear that the reduction in RTs from the $50 \mathrm{msec}$ to the $150 \mathrm{msec}$ SOA is much greater when the cues and targets are in the same modality than when they are in different modalities. Furthermore, at each SOA-validity combination, the RTs to the target tended to be slower when the target and cue were in the same modality than when they were in different modalities. A similar effect of combining cue and target modalities was found with visual and auditory stimuli, even when the validity of the cue was ineffectual because an auditory target was used [2]. One interpretation of this observation is that the processing of a cue in a given modality interferes more with subsequent processing of a second stimulus if it is in the same modality than if it is in a different modality. An alternative (but not mutually exclusive) interpretation of these findings is that the subject in this kind of task has to inhibit an overt response to the cue (a response that would be classified as an anticipation) and this inhibition is not yet dissipated if a second stimulus in the same modality arrives within a critical time interval; stimuli in other modalities would presumably be less effected by this inhibitory process. 
The findings presented here previously [2] imply that the mechanisms controlling shifts of attention are closely linked to orienting systems, such as those of the eye and hand, to which cues from various modalities provide imputs. Since this view assumes that the system controlling spatial shifts of attention has polysensory inputs, it would be worthwhile to examine the results of studies that have investigated spatial attentional disorders in more than one modality. Spatial attentional disorders following unilateral cerebral lesions are manisfested as unilateral spatial neglect or as sensory extinction, i.e. failure to report a stimulus presented on the side contralateral to the lesion when a second stimulus is simultaneously presented on the ipsilateral side. Extinction to visual, auditory or tactile stimuli, both within and between these modalities, has been frequently described in patients with unilateral cerebral disease, especially when it affects posterior regions of the right hemisphere [12]. When more than one modality is involved, which is often the case, clinicians usually infer that the lesion affects more than one cerebral lobe and that the disorder is caused by a defect in sensory analysis [8]. If the lesion is localized to one lobe, it usually involves polysensory areas such as the posterior parietal region $[1,11,15]$, or, in monkeys with unilateral excisions, the superior temporal sulcus [13]. In these investigations the modalities in which extinction has been reported are usually vision and touch. However, there has been no systematic investigation of the frequency of separate vs combined occurrence of tactile and visual extinction. In an investigation of the frequency of auditory and visual extinction in patients with unilateral cerebral stroke, DeRenzi et al. [6] reported that although auditory extinction was fairly common, it is rarely found in combination with visual extinction, and is associated with lesions interrupting auditory pathways rather than with damage to polysensory areas, and therefore has a sensory rather than attentional origin. This finding is consistent with our proposed explanation for the absence of intra- and intermodal validity effects with auditory targets. Unilateral spatial neglect is manifested as a disorder of exploring one side of space [5]. The two studies that have investigated visual and tactile neglect (by manual search in the absence of vision) in patients with unilateral cerebral disease failed to find positive associations between these two forms of neglect $[3,24]$. Thus, these findings are not consistent with the idea that unilateral neglect is caused by a disorder of a polysensory attentional mechanism.

Another issue raised by our findings concerns the apparent discrepancy between our findings of intermodal validity effects and the failure of POSNER et al. [17] to find such effects when simple RT tasks are employed. It seems likely that the discrepancy is due to differences in the experimental situations, in particular to the use of spatial cues in our situation as opposed to the symbolic, centrally presented cues that Posner employed. It is possible that symbolic directional cues presented in central vision do not activate the brain mechanisms that mediate intermodal effects in spatial attention that are found with lateralized spatial cues.

Acknowledgements - The research supported here was supported by a grant to H.A.B. from the Veterans' Administration Department of Medicine and Surgery. We thank Dean Galatis for programming and apparatus construction, and Jeannie Tramontin for editorial assistance.

\section{REFERENCES}

1. Brain, R. Visual disorientation with special reference to lesions of the right cerebral hemisphere. Brain 64, $244-272,1941$.

2. Blchtel, H. A. and Butter, C. M. Spatial attentional shift: implications for the role of polysensory mechanisms. Neuropsychologia 26, 499-509, 1988. 
3. Chedru, F. Spatial representation in unilateral spatial neglect. Cortex 39, 1057-1061, 1976.

4. Crovitz, H. F. and Daves, W. Tendencies to eye movements and perceptual accuracy. J. exp. Psych.63, $495-498,1962$.

5. DeRenzi, E. Disorders of Space Exploration and Cognition. Wiley, New York, 1982.

6. DeRenzi, E. Gentilini, M. and Pattacinl, F. Auditory extinction following hemisphere damage. Neuropsychologia 22, 733-744, 1984.

7. Eriksen, C. W. and Hoffman, J. E. The extent of processing of noise elements. Percept. Psychophys. 14, $155-160,1973$.

8. Frederiks, J. A. M. Disorders of attention in neurological syndromes. In Handbook of Clinical Neurology, Vol. 3, P. J. VinkeN and G. W. BruYn (Editors), pp. 187-201. New York, Wiley 1969.

9. GoldBerg, M. E. and Bushnell, M. C. Behavioral enhancement of visual responses in the monkey cerebral cortex. II. Modulation in frontal eye fields specifically related to saccades. J. Neurophysiol. 46, 773-787, 1981.

10. GULdiekG, M.E. and WurI L, R. H. Activity of superior colliculus in behaving monkey. II. Effect of selective attention on neuronal responses. $J$. Neurophysiol. 35, $560574,1972$.

11. Hécafn, H., Penfield, W., Bertrand, C. and Malmo, R. The syndrome of apractagnosia due to lesions of the minor cerebral hemisphere. Archs Neurol. Psychiat. 75, 400-434, 1956.

12. Heilman, K. M., Watson, R. T., and Valenstein, E. Neglect and related disorders. In Clinical Neurology, 2nd edn, K. M. Heilman and E. Valenstein (Editors). Oxford University Press, New York, 1985

13. LUh, K. E., BUtTER, C. M. and BuChteL, H. A. Impairments in orienting to visual stimuli in monkeys following unilateral lesions of the superior sulcal polysensory cortex. Neuropsychologia 24, 461-470, 1986.

14. Matelli, M., Olivieri, M. F., Sacani, A., and Rizzolatti, G. Upper visual space neglect and motor deficits after section of the midbrain commissure in the cat. Behav. Brain. Res. 10, 263 285, 1983.

15. PatTerson, A. and ZaNGwiLl, D. L. Disorders of visual space perception associated with lesions of the right cerebral hemisphere. Brain 67, 331-358, 1944.

16. Posner, M. I. Chronometric Explorations of the Mind. Lawrence Erlbaum, Hillsdale, New Jersey, 1978.

17. Posncr, M. I. Orienting of attention. Q.J. exp. Psychol. 32, 3 25, 1980.

18. Posner, M. I., Cohen, A. and Rafal, R. Neural systems control of spatial orienting. Phil. Trans. R. Soc. Lond. 298, 187-198, 1982.

19. Posner, M. I. Crippin. P. J., Cohen, A. and Rafal, R. Speed of covert orienting of attention and express saccades. Paper presented at annual meeting of the Psychonomic Society, New Orleans, Louisiana, November, 1986.

20. Posner, M. I., Nissen, M. and Ogden, W. C. Attended and unattended processing modes: the role for spatial location. In Modes of Perception, H. J. PICK (Editor). Lawrence Erlbaum, Hillsdale, New Jersey, 1977.

21. Posner, M. I., Nissen, M. and SNyder, C. R. Relationships between attention shifts and saccadic eye movements. Paper presented at annual meeting of the Psychonomic Society. San Antonio, Texas, November, 1978.

22. Remington, R. W. Attention and saccadic eye movements. J, exp. Psychol: Hum. Percept. Perform. 6, 726-744, 1980.

23. SINGER, W. ZlHL, J. and PöPPEL, E. Suhcortical control of visual thresholds in humans: evidence for modality specific and retinotopically organized mechanisms of selective attention. Exp. Brain. Res. 29, 173-190, 1977.

24. Villakdita, C. Tactile exploration of space and visual neglect in brain-damaged patients. J. Neurol. 234, $292297,1987$.

25. WURTZ, R. H. and Mohler, C. W. Organization of monkey superior colliculus: enhanced visual responses of superficial layer cells. J. Neurophysiol. 39, 745-762, 1976.

26. Wurtz, R. H. and Mohler, C. W. Enhancement of visual responses in monkey striate cortex and frontal eye fields. J. Neurophysiol. 39, 766 787, 1976. 